\title{
Thirty-Day Mortality in Septic Shock Patients is Directly Associated with High Disease Severity Score but not with the Length of Stay in the Emergency Department
}

\author{
(D) Gülseren Elay¹, (1) Behçet Al2 \\ 1Department of Medical Intensive Care Unit, Gaziantep University, Gaziantep, Turkey \\ 2Department of Emergency Medicine, Faculty of Medicine, Gaziantep University, Gaziantep, Turkey
}

\begin{abstract}
Aim: To determine the factors associated with mortality in septic shock patients who are transferred from the emergency department (ED) to the intensive care unit (ICU).

Materials and Methods: We used the data of 206 patients who were admitted to the ED with infection and were diagnosed with septic shock between December 2016 and January 2020.

Results: The 206 patients had a mean Glasgow Coma score of 11.42 (range: 3-15), mean Acute Physiology and Chronic Health Evaluation (APACHE-II) score of 21.66 (range: 8-49) and mean Sequential Organ Failure Assessment Score (SOFA) of 10.24 (range: 2-22). There were no differences in 30-day mortality and in need for renal replacement therapy (RRT) or mechanical ventilation (MV) between patients transferred to the ICU within 1 hour of ED admission and those transferred to the ICU more than 6 hours after ED admission ( $p>0.05)$. Patients with an APACHE-II score $\geq 20$ or a SOFA score $\geq 8$ had longer MV duration and ICU and hospital stay, greater RRT and MV need and higher mortality rate than the patients with lower value $(p<0.05)$.
\end{abstract}

Conclusion: Septic shock patients who have high disease severity scores have poor prognosis. The length of time between ED and ICU admission does not affect patient outcomes.

Keywords: Septic shock, emergency department, admission time, mortality

\section{Introduction}

Sepsis, an urgent condition, causes life-threatening organ dysfunction due to dysregulated host response to infection (1). According to the World Health Organization, approximately thirty million people suffer from sepsis each year globally, with approximately six million sepsis deaths (2). Despite adequate fluid resuscitation, vasopressor need to maintain a mean arterial pressure $\geq 65 \mathrm{mmHg}$, and a serum lactate level $>2 \mathrm{mmol} / \mathrm{L}$ called septic shock which is a more serious stage of sepsis. Septic shock inhospital mortality is in excess of $40 \%$ (1). The incidence, morbidity, and mortality of septic shock are much higher in developing countries, like Turkey. Most septic shock cases are diagnosed in emergency department (ED), and is inherently difficult to manage due to the advanced hemodynamic monitorization need. Early diagnosis and treatment are key to prevent mortality $(3,4)$. Septic shock patients are normally transferred to an intensive care unit (ICU) after ED diagnosis. The first six hours after shock onset are regarded as the "golden hours" for intervention. We hypothesize that, septic shock patients who are treated in ICU during the first six "golden hours" will have better outcomes. The present study investigates factors contributing to the morbidity and mortality of septic shock patients. 


\section{Materials and Methods}

In this retrospective study, participants were recruited from the ED of Gaziantep University Faculty of Medicine Hospital, who all presented between December 2016 and January 2020 and were diagnosed with septic shock based on the Sepsis-3 criteria. A total of 206 patients were included in this study (Figure 1).

In this ED approximately 250,000 patients are treated per year. Study data were retrieved from the hospital's electronic record system. Study participants were diagnosed with septic shock within one hour of admission at the ED, treated shortly after diagnosis, and had to be transferred to the ICU for further treatment; detailed inclusion criteria are described below. Septic shock was diagnosed in sepsis patients who met the following criteria (3): (i) mean arterial pressure be maintained at $\geq 65 \mathrm{mmHg}$ by vasopressor, despite adequate fluid resuscitation, and (ii) serum lactate level $>2 \mathrm{mmol} / \mathrm{L}$. The following data were recorded for all included study participants: demographics, disease severity scores, comorbidities, antibiotic administration, blood culture results, length of hospital stay, and 30-day mortality. Sequential Organ Failure Assessment (SOFA) and Acute Physiology and

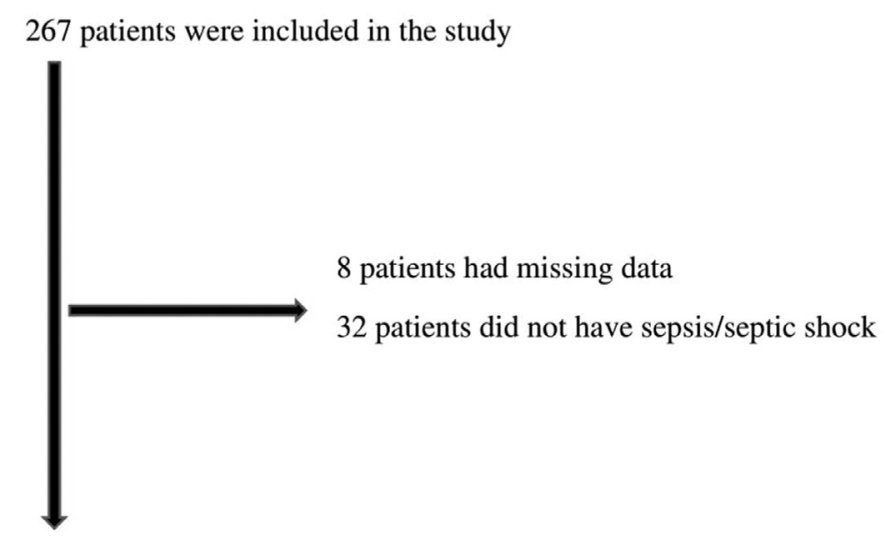

227 patients were eligible

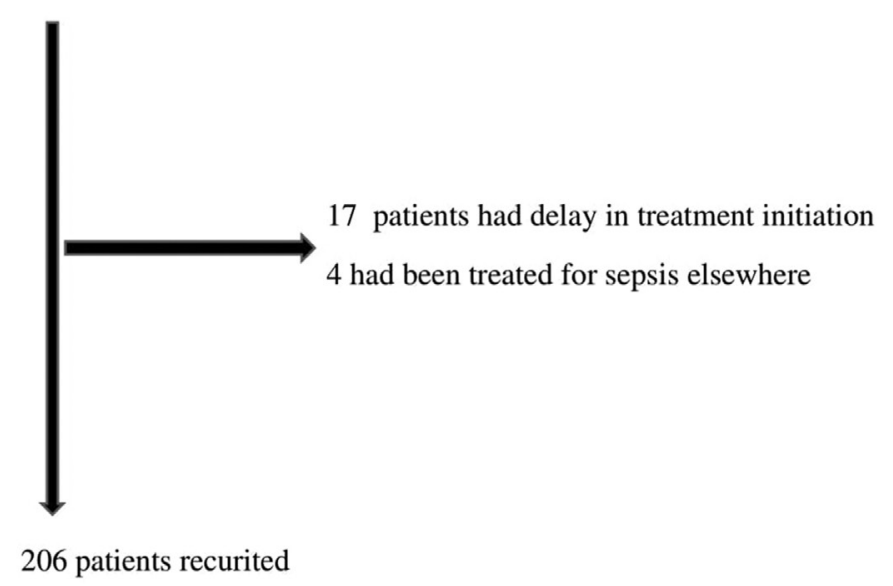

Figure 1. Description of patient enrolment
Chronic Health Evaluation (APACHE) II were calculated at ICU admission. The study was done in tertiary stage medical ICU. Informed consent for the study was taken from patients or their relatives by calling phone.

\section{Inclusion Criteria}

Patients were recruited as study participants if they met all the following inclusion criteria: (i) aged 18 years or more, (ii) presented to the study center ED due to infection, (iii) diagnosed with septic shock, according to Sepsis-3 criteria, within one hour of admission in ED, (iv) expected to survive for longer than 24 hours after septic shock diagnosis, (v) consented to receiving septic shock treatment, and (vi) received appropriate antibiotic treatment within one hour, (vii) moved to ICU. All study participants gave informed consent to be included in the study.

\section{Exclusion Criteria}

Patients were excluded from the study if they met one or more of the following criteria: (i) not diagnosed with septic shock according to Sepsis-3 criteria, (ii) had been treated for sepsis elsewhere prior to presenting at the study center for further treatment, (iii) contraindication for diagnostic tests, (iv) had suffered delay in treatment initiation, (v) fluid or antibiotic treatment contraindicated for any reason, moribund patients.

\section{Statistical Analysis}

Data were analyzed using frequency, percentage, and descriptive statistics using SPSS 22.0 software. Comparisons were made using a chi-square test for categorical variables and a Mann-Whitney $U$ test for continuous variables. Values of $p<0.05$ were accepted as statistically significant.

\section{Ethical Consideration}

Ethical approval for this study was obtained from the Clinical Research and Ethical Committee of Gaziantep University (approval no: 2019/472, date: 25.12.2019).

\section{Results}

The study had a total of 206 participants, with the following demographics: (i) mean age 65.67 years (20-100), and (ii) 117 (56.8\%) were male and 89 (43.2\%) were female. Study participants had a mean duration of MV support of 3.22 days (0-42), and they had the following mean clinical scores: Glasgow coma score of 11.42 (3-15), APACHE-II score of 21.66 (8-49), and SOFA score of 10.24 (2-22). Study participants received antibiotic treatment for a mean of 9.01 days (1-45), and antifungal treatment for a mean of 2.76 days (0-46). Ninety-nine study participants (48.0\%) had an APACHE-II score $\geq 20,144$ (69.9\%) had a SOFA score $\geq 8$, and 
40 (19.42\%) had a lactate level $\geq 4 \mathrm{mmol} / \mathrm{L}$. Eighty-seven study participants (42.23\%) were transferred to the ICU within one hour of admission to the ED, while 51 (24.76\%) were transferred to the ICU more than six hours after presenting to the ED. MV was required by 109 (52.91\%) study participants, and RRT by 27 (13.11\%). The median interval between ED admission and ICU admission was two hours (1-5), the median ICU stay length was eight days (3-14.25), and the mean hospital stay length was nine days (1-50) (Table 1).

\begin{tabular}{|c|c|}
\hline & Overall patients $(n=206)$ \\
\hline Age & $65.67(20-100)$ \\
\hline \multicolumn{2}{|l|}{ Gender $\mathbf{n}(\%)$} \\
\hline Male/female & $117(56.8) / 89(43.2)$ \\
\hline \multicolumn{2}{|l|}{ Score } \\
\hline GCS & $11.42(3-15)$ \\
\hline APACHE- II & $21.66(8-49)$ \\
\hline SOFA & $10.24(2-22)$ \\
\hline Lactate $\geq 4 \mathrm{mmolL}^{-1}$ at admission to ICU & $40(19.42)$ \\
\hline APACHE $-2 \geq 20$ at admission to ICU & $99(48.06)$ \\
\hline SOFA $\geq \mathbf{8}$ at admission to ICU & $144(69.90)$ \\
\hline \multicolumn{2}{|l|}{ Comorbidities n (\%) } \\
\hline Chronic respiratory disease & $32(15.53)$ \\
\hline Solid organ malignancy & $44(21.36)$ \\
\hline Liver disease & $14(6.80)$ \\
\hline Hematological malignancy & $51(24.75)$ \\
\hline Immunosupression & $49(23.78)$ \\
\hline Diabetus mellitus & $26(12.62)$ \\
\hline \multicolumn{2}{|l|}{ Therapies, n (\%) } \\
\hline MV & $109(52.91)$ \\
\hline Vasopressor & $139(67.48)$ \\
\hline RRT & $27(13.11)$ \\
\hline Admission to ICU within an hour & $87(42.23)$ \\
\hline Admission to ICU after six hours or later & $51(24.76)$ \\
\hline ED admission to ICU transfer time & $2(1-5)$ \\
\hline \multicolumn{2}{|l|}{ Length of stay (days) } \\
\hline MV & $3.32(0-42)$ \\
\hline ICU & $8(3-14.25)$ \\
\hline Hospital & $9.67(1-50)$ \\
\hline Duration of antibiotic therapy (days) & $9.01(1-45)$ \\
\hline Duration of antifungal therapy (days) & $2.76(0-46)$ \\
\hline 30-day mortality & $133(64.56)$ \\
\hline \multicolumn{2}{|c|}{$\begin{array}{l}\text { GCS: Glascow coma score, APACHE-II: Acute Physiology and Chronic Health Evaluation } \\
\text { II, SOFA: The Sequential Organ Failure Assessment, ED: Emergency department, ICU: } \\
\text { Intensive care unit, RRT: Renal replacement therapy, MV: Mechanical ventilation, n: } \\
\text { Number, Data are presented as median (minimum-maximum). }\end{array}$} \\
\hline
\end{tabular}

A total of 133 (64.56\%) study participants died within 30 days of septic shock diagnosis. In our study, 70 (33.98\%) of participants had lung infection, 53 (25.73\%) had abdominal infection, 25 (12.14\%) had central nervous system infection, and 18 (8.73\%) had urinary tract infection (Table 2).

Participants who had APACHE-II score $\geq 20$ or a SOFA score $\geq 8$ had statistically significant higher 30-day mortality, greater RRT and MV need, and longer MV, ICU and hospital day compared to participants who had APACHE-II score $<20$ or a SOFA score $<8$ $(\mathrm{p}<0.05)$ (Table 3).

There were no statistically significant differences regarding 30day mortality, RRT need, or MV need between participants who were transferred from ED to ICU within one hour of admission and those who were transferred after at least six hours of admission $(p>0.05)$. Participants with lactate level $\geq 4 \mathrm{mmol} / \mathrm{L}$ had greater RRT and MV need $(p<0.05)$ than those whose lactate level was $<4 \mathrm{mmol} / \mathrm{L}$ (Table 4 ).

\begin{tabular}{|c|c|}
\hline Source of infection & n (\%) \\
\hline Lung & 70 (33.98) \\
\hline Abdomen & $53(25.73)$ \\
\hline Urinary tract & $18(8.73)$ \\
\hline Central nervous system & $25(12.14)$ \\
\hline Soft tissue & $7(3.40)$ \\
\hline \multicolumn{2}{|l|}{ Isolated microorganisms n (\%) } \\
\hline Culture-negative-infected patients & $60(29.13)$ \\
\hline Aspergillus spp. & $2(0.97)$ \\
\hline Candida spp. & $24(11.65)$ \\
\hline Escherichia coli & $41(19.90)$ \\
\hline Pseudomonas spp. & $20(9.71)$ \\
\hline Acinetobacter spp. & $48(23.30)$ \\
\hline Klebsiella pneumonia & $32(15.53)$ \\
\hline Enterococcus spp. & $40(19.42)$ \\
\hline Staphylococcus aureus & $62(30.10)$ \\
\hline Streptococcus spp. & $2(0.97)$ \\
\hline \multicolumn{2}{|l|}{ Antimicrobial used } \\
\hline Quinolone & $49(23.79)$ \\
\hline Macrolides & $75(36.41)$ \\
\hline Cephalosporin & $134(65.05)$ \\
\hline Meronem & $130(63.11)$ \\
\hline Vanko & $91(44.17)$ \\
\hline Teicoplanin & $5(2.42)$ \\
\hline Colistin & $27(13.11)$ \\
\hline
\end{tabular}




\begin{tabular}{|c|c|c|c|}
\hline & MV (day) & $\begin{array}{l}\text { Length of } \\
\text { ICU stay } \\
\text { (day) }\end{array}$ & $\begin{array}{l}\text { Length of } \\
\text { hospital stay } \\
\text { (day) }\end{array}$ \\
\hline \multicolumn{4}{|c|}{ ED to ICU admission time in 1 hour } \\
\hline Yes & $1(1-4)$ & $7(3-12)$ & $9(3-17)$ \\
\hline \multirow[t]{2}{*}{ No } & $1(1-2)$ & $6(3-12)$ & $8(4-13)$ \\
\hline & $p=0.215$ & $p=0.716$ & $p=0.807$ \\
\hline \multicolumn{4}{|c|}{ ED-ICU admission time $\geq 6$ hours } \\
\hline Yes & $1(0-6)$ & $7(4-13)$ & $9(5-13)$ \\
\hline \multirow[t]{2}{*}{ No } & $1(0-2)$ & $7(3-12)$ & $8(3-16)$ \\
\hline & $p=0.345$ & $p=0.415$ & $p=0.801$ \\
\hline \multicolumn{4}{|c|}{ APACHE-II $\geq 20$} \\
\hline Yes & $1(1-6)$ & $6(2-12)$ & $6(2-12)$ \\
\hline \multirow[t]{2}{*}{ No } & $0(0-1)$ & $7(4-13)$ & $9(5-18)$ \\
\hline & $p=0.000$ & $p=0.036$ & $p=0.001$ \\
\hline \multicolumn{4}{|c|}{ SOFA $\geq 8$} \\
\hline Yes & $1(0-4)$ & $6(2.25-12)$ & $7(3-13.75)$ \\
\hline \multirow[t]{2}{*}{ No } & $0(0-2)$ & $9(5-13.25)$ & $9(6-17.25)$ \\
\hline & $p=0.000$ & $p=0.010$ & $p=0.005$ \\
\hline \multicolumn{4}{|c|}{ Lactate $\geq 4 \mathrm{mmolL}^{-1}$} \\
\hline Yes & $1(0-3)$ & $4.5(2.25-10)$ & $5(3-11)$ \\
\hline \multirow[t]{2}{*}{ No } & $0(0-2.25)$ & $7(3.75-13)$ & $9(4-16)$ \\
\hline & $p=0.127$ & $p=0.070$ & $p=0.064$ \\
\hline \multicolumn{4}{|c|}{$\begin{array}{l}\text { ED: Emergency department, ICU: Intensive care unit, APACHE-II: Acute Physiology } \\
\text { and Chronic Health Evaluation II, SOFA: The Sequential Organ Failure Assessment, } \\
\text { MV: Mechanical ventilation unit, n: Number, Data are presented as median } \\
\text { (minimum-maximum). }\end{array}$} \\
\hline
\end{tabular}

\section{Discussion}

This study revealed no statistically significant differences in RRT or MV need, or 30-day mortality between study participants who were transferred from the ED to the ICU within one hour of ED admission and those transferred after more than six hours $(p>0.05)$. The first six-hour time-points were chosen because the first six hours have been determined to be the most critical timewindow for effective intervention (5). Intervention for septic shock should be fast, with rapid determination of source of infection. Angus (6) reported that the infection side is respiratory tract in half of cases, followed by intra-abdominal infection and urinary tract. Baykara et al. (7) conducted a study in 132 ICUs in Turkey and reported that respiratory tract was the most common (71.60\%) side of infection in septic shock. Our study revealed a much lower incidence of respiratory tract infection (33.98\%); we hypothesize difference is due to comorbidities and regional/local differences. Because the study by Baykara et al. (7), had been performed mostly on surgical ICU patients, but our study conducted in
Table 4. Outcomes of early-late ICU admission time, high disease severity scores and lactate level

\begin{tabular}{|l|l|l|l|l|}
\hline & $\begin{array}{l}\text { 30-day } \\
\text { mortality n (\%) }\end{array}$ & $\begin{array}{l}\text { Vasopressor } \\
\text { n (\%) }\end{array}$ & $\begin{array}{l}\text { RRT } \\
\text { n (\%) }\end{array}$ & $\begin{array}{l}\text { MV } \\
\text { n (\%) }\end{array}$ \\
\hline
\end{tabular}

ED to ICU transfer within 1 hour

\begin{tabular}{|c|c|c|c|c|}
\hline Yes & $55(63.2)$ & $60(69.0)$ & $11(12.6)$ & $49(56.3)$ \\
\hline \multirow[t]{2}{*}{ No } & $32(36.8)$ & $27(31.0)$ & $76(87.4)$ & $38(43.7)$ \\
\hline & $p=0.730$ & $p=0.696$ & $p=0.866$ & $p=0.402$ \\
\hline \multicolumn{5}{|c|}{ ED to ICU transfer $\geq 6$ hours passed } \\
\hline Yes & $34(66.7)$ & $35(68.6)$ & $3(5.9)$ & $30(58.8)$ \\
\hline \multirow[t]{2}{*}{ No } & $17(33.3)$ & $16(31.4)$ & $48(94.1)$ & $21(41.2)$ \\
\hline & $p=0.717$ & $\mathrm{p}=0.840$ & $p=0.078$ & $p=0.330$ \\
\hline \multicolumn{5}{|c|}{ APACHE-II $\geq 20$} \\
\hline Yes & $73(73.7)$ & $73(73.7)$ & $18(18.2)$ & $77(77.8)$ \\
\hline \multirow[t]{2}{*}{ No } & $26(26.3)$ & $26(26.3)$ & $81(81.8)$ & $22(22.2)$ \\
\hline & $p=0.008$ & $p=0.065$ & $p=0.038$ & $p=0.001$ \\
\hline \multicolumn{5}{|c|}{ SOFA $\geq 8$} \\
\hline Yes & $100(69.4)$ & $102(70.8)$ & $24(16.7)$ & $92(63.9)$ \\
\hline \multirow[t]{2}{*}{ No } & $44(30.6)$ & $42(29.2)$ & $120(83.3)$ & 52 (36.1) \\
\hline & $p=0.026$ & $p=0.117$ & $p=0.021$ & $p=0.001$ \\
\hline \multicolumn{5}{|c|}{ Lactate $\geq 4$} \\
\hline Yes & $24(60.0)$ & $28(70.0)$ & $10(25)$ & $28(70)$ \\
\hline \multirow[t]{2}{*}{ No } & $16(40.0)$ & $12(30.0)$ & $30(75)$ & $12(30)$ \\
\hline & $p=0.502$ & $p=0.704$ & $p=0.013$ & $p=0.016$ \\
\hline
\end{tabular}

ED: Emergency department, ICU: Intensive care unit, APACHE-II: Acute Physiology and Chronic Health Evaluation II, SOFA: The Sequential Organ Failure Assessment, MV: Invasive mechanical ventilation, RRT: Renal replacement therapy, n: Number

medical ICU. Our results indicate that participants with higher disease severity scores had poorer prognoses. Nearly half (48\%) of the study participants had an APACHE-II score $\geq 20$, while $69 \%$ had a SOFA score $\geq 8$. It is important to note that only patients who had not been treated for sepsis anywhere except the study center were included in the study. Our study participants had a mean age of 66 years, and a significant number were already diagnosed with hematological or solid cancers. Septic shock symptoms are often obscure in elderly and immunosuppressed patients, so the disease can go undetected by patients and relatives. Patients with cancer, chronic liver disease, or diabetes, immunsuppression have a greater tendency to develop sepsis, and they have high mortality (6). Previous studies show that a high disease severity score is important and associated with greater mortality $(8,9)$. A study of septic shock patients by Labelle et al. (8) found APACHE-II score to be a key determinant of mortality. In another large-scale retrospective study of 14,788 patients, higher in-hospital mortality was reported among patients who waited more than 2.4 hours for ICU admission; this association strengthened with higher APACHEIV score (9). The time taken to be admitted to ICU following ED admission varies geographically and even between hospitals in 
the same geographic region $(10,11)$. To the best of our knowledge, there is no nationwide study reporting the average time interval between ED and ICU admission of septic shock patients in Turkey. Mahsanlar et al. (12) found the mean length of stay of general patients in EDs to be 6.5 hours. Erkuran et al. (13) conducted study with 2,380 general patients, found a mean length of stay in ED 1.23 hours (10 minutes - 10.02 hours). In our study, the median delay time was two hours (1-5 hours). Since this time was relatively short, we could not find any relationship between delay time and mortality.

Vilella and Seifert (14) reported higher in-hospital mortality; with higher APACHE-II score, also reported mortality being 2.5 times higher in patients whose lactate level was $>2.5 \mathrm{mmol} / \mathrm{L}$ in sepsis patients. Lactate is a known indicator of tissue hypoperfusion that has developed as a result of circulatory collapse, and it has been reported that increased lactate levels negatively affect prognosis (1). Casserly et al. (15) revealed a linear relationship between lactate level and mortality, and that lactate levels $\geq 4$ $\mathrm{mmol} / \mathrm{L}$ are associated with significantly increased mortality. Since the current study defined sepsis using the current Sepsis-3 criteria, patients were only recruited to the study if their lactate level $\geq 2 \mathrm{mmol} / \mathrm{L}$. Consistent with the literature, the current study found that participants whose lactate level $\geq 4 \mathrm{mmol} / \mathrm{L}$ had increased MV and RRT times. In the current study, the ICU mortality rate was $64.56 \%$, while the largest current study of septic shock patients in Turkey reported an ICU mortality rate of 75.9\%, based on the Sepsis-3 criteria (7). ICU mortality rates from studies of septic shock patients in other countries include $55.7 \%$ in Brazil and $64.6 \%$ in India $(16,17)$. The mortality rate found in the current study is much lower than expected considering that all study participants were diagnosed with septic shock at ED admission, and that a significant percentage also had high disease severity scores and serious comorbidities. The results showed that delayed transfer to ICU was not related to mortality; this may be due to prompt and proper medical intervention in the ED. Non-intensivists play a very important role in the timely and appropriate management of sepsis patients, with the pre-hospitalization phase being critical $(18,19)$. Pre-hospital healthcare providers treat more cases of sepsis than of acute myocardial infarction or stroke (20). Studies have shown that prehospital care play a key role in the early diagnosis and treatment of sepsis (21). Both the USA and Canada have implemented a pre-hospital diagnosis and treatment initiation protocol for sepsis patients (22); in particular, the USA has initiated the prehospital sepsis project and implemented web-based education for physicians (23). To our knowledge, there is no specific prehospital diagnosis or treatment initiation protocol for sepsis patients in Turkey. Intense patient and physician education would be effective for initiation of early sepsis interventions and would likely reduce sepsis patient mortality.

\section{Study Limitations}

The study took a retrospective, single-centered design, and it included a relatively low number of patients (206 participants) due to the strict study inclusion and exclusion criteria. Study participants had been diagnosed with septic shock according to Sepsis-3 criteria, and were transferred from the ED to the ICU. Furthermore, each participant was administered the most appropriate broad-spectrum antibiotic for their infection focus, with antibiotic selection revised according to tissue culture results. Information was unavailable regarding pre-hospital interventions prior to ED admission.

\section{Conclusions}

This study indicates ED patients diagnosed with septic shock; with high APACHE-II score, high SOFA score, and elevated lactate levels have a poor prognosis. However, prognosis is independent from ED to ICU transfer time. We believe that, septic shock patients will have improved outcomes if they present to the ED before developing septic shock, and since signs of sepsis may be obscure in elderly and immunosuppressed patients, patient education is needed to increase awareness of sepsis.

\section{Ethics}

Ethics Committee Approval: Ethical approval for this study was obtained from the Clinical Research and Ethical Committee of Gaziantep University (approval no: 2019/472, date: 25.12.2019).

Informed Consent: Informed consent for the study was taken from patients or their relatives by calling phone.

Peer-review: Externally peer-reviewed.

\section{Authorship Contributions}

Surgical and Medical Practices: G.E., Concept: G.E., B.A., Design: G.E., B.A., Data Collection or Processing: G.E., B.A., Analysis or Interpretation: G.E., B.A., Literature Search: G.E., Writing: G.E.

Conflict of Interest: No conflict of interest was declared by the authors.

Financial Disclosure: This research received no specific grant from any funding agency in the public, commercial, or not-forprofit sectors.

\section{References}

1. Singer M, Deutschman CS, Seymour C, Shankar-Hari M, Annane D, Bauer M, et al. The Third International Consensus Definitions for Sepsis and Septic Shock (Sepsis-3) JAMA - J Am Med Assoc. 2016;315:801-10. 
2. Reinhart K, Daniels R, Kissoon N, Machado FR, Schachter RD, Finfer S. Recognizing sepsis as a global health priority - A WHO Resolution. N Engl J Med. 2017;377:414-7.

3. Tupchong K, Koyfman A, Foran M. Sepsis, severe sepsis, and septic shock: A review of the literature. African J Emerg Med. 2015;2:127-35.

4. Rhodes A, Evans LE, Alhazzani W, Levy MM, Antonelli M, Ferrer R, et al. Surviving Sepsis Campaign: International Guidelines for Management of Sepsis and Septic Shock: 2016. Crit Care Med. 2017;45:486-552.

5. Mathieu Jozwiak, Xavier Monnet1, Jean-Louis Teboul. Implementing sepsis bundles. Ann Transl Med. 2016;4:332.

6. Angus DC, van der Poll T. Severe sepsis and septic shock. N Engl J Med. 2013;369:840-51

7. Baykara N, Akalin H, Arslantaș MK, Hanci V, Çağlayan Ç, Kahveci F, et al. Epidemiology of sepsis in intensive care units in Turkey: a multicenter, pointprevalence study. Crit Care. 2018;22:93.

8. Labelle A, Juang P, Reichley R, Micek S, Hoffmann J, Hoban A, et al. The determinants of hospital mortality among patients with septic shock receiving appropriate initial antibiotic treatment. Crit Care Med. 2012;40:2016-21.

9. Groenland CNL, Termorshuizen F, Rietdijk WJR, van den Brule J, Dongelmans DA, de Jonge E, et al. Emergency Department to ICU Time Is Associated with Hospital Mortality: A Registry Analysis of 14,788 Patients From Six University Hospitals in The Netherlands. Crit Care Med. 2019;47:1564-71.

10. Carter AW, Pilcher D, Bailey M, Cameron P, Duke GJ, Cooper J. Is ED length of stay before ICU admission related to patient mortality? Emerg Med Australas. 2010;22:145-50.

11. Thijssen WAMH, Kraaijvanger N, Barten DG, Boerma MLM, Giesen P, Wensing M. Impact of a well-developed primary care system on the length of stay in emergency departments in the Netherlands: a multicenter study. BMC Health Serv Res. 2016;16:149.

12. Mahsanlar Y, Parlak I, Yolcu S, Akay S, Demirtas Y, Eryigit V. Factors Affecting the Length of Stay of Patients in Emergency Department Observation Units at Teaching and Research Hospitals in Turkey. Turk J Emerg Med. 2016;14:3-8.
13. Erkuran MK, Duran A, Ocak T, Citisli V, Kaya H. The impact of the duration of admission to the emergency room on the mortality of intensive care patients. Niger J Clin Pract. 2014;17:320-3.

14. Vilella AL, Seifert CF. Timing and appropriateness of initial antibiotic therapy in newly presenting septic patients. Am J Emerg Med. 2014;32:7-13. [Epub 2013 Oct 17].

15. Casserly B, Phillips GS, Schorr C, Dellinger RP, Townsend SR, Osborn TM, et al. Lactate measurements in sepsis-induced tissue hypoperfusion: results from the Surviving Sepsis Campaign database. Crit Care Med. 2015;43:567-73.

16. Machado F, Cavalcanti A, Bozza F, Angus D, Ferreira E, Carrara F, et al. Epidemiology of sepsis in brazilian icus: a nationwide stratified sample. Intensive Care Medicine Experimental 2015;3:A642.

17. Todi S, Chatterjee S, Bhattacharyya M. Epidemiology of severe sepsis in India. Crit Care 2007. DOI: doi.org/10.1186/cc5225

18. Daniels R. Surviving the first hours in sepsis: Getting the basics right (an intensivist's perspective). J Antimicrob Chemother. 2011;66:11-23.

19. Seymour CW, Rea TD, Kahn JM, Walkey AJ, Yealy DM, Angus DC. Severe sepsis in pre-hospital emergency care: analysis of incidence, care, and outcome. Am J Respir Crit Care Med. 2012;186:1264-71. [Epub 2012 Oct 18].

20. Wang HE, Weaver MD, Shapiro NI, Yealy DM. Opportunities for emergency medical services care of sepsis. Resuscitation. 2010;81:193-7.

21. Nguyen HB, Rivers EP, Abrahamian FM, Moran GJ, Abraham E, Trzeciak S, et al. Severe sepsis and septic shock: review of the literature and emergency department guidelines. Ann Emerg Med. 2006;48:28-54.

22. Sibley AK, Sibley DS. Total infection. Recognizing \& treating sepsis in the field. JEMS. 2007;32:64-6.

23. Baez AA, Hanudel P, Wilcox SR. The prehospital sepsis project: Out-ofhospital physiologic predictors of sepsis outcomes. Prehosp Disaster Med. 2013;28:632-5. 